\title{
A Knowledge Management System for E-government Projects and Actors
}

\author{
Roberta Morici, Eugenio Nunziata, and Gloria Sciarra \\ Irso-Butera e Partners, Via Maria Cristina, 2, 00196, Rome, Italy \\ \{morici, nunziata, sciarra\} @irso-bep.it
}

\begin{abstract}
The paper presents a knowledge management system designed for the Italian Department of Technology and Innovation (Dipartimento per l'Innovazione e le Tecnologie, www.mininnovazione.it) The Department need is to promote the realization of e-government projects on a local basis, supporting all actors involved in the design and implementation of egovernment projects in Italy. In the pursue of this objective, the Department needs at the same time to maintain consistence among e-government projects, without restricting the freedom of Local Authorities, who are autonomous in carrying out their projects. In this scenario, a knowledge management system has been designed to support work and knowledge sharing for all actors involved, who will have a chance to re-use experiences, to be guided in the projects implementation, and to join a community of people involved in egovernment projects. Since the system is oriented to support different groups of users, for each of them a specific online environment has been designed. Members of departmental e-government projects, innovators within Local Authorities, Internet users, all have the chance to share resources on egovernment: the higher involvement, the more resources are available. At the core of the system, there are private rooms designed as working environments for those strictly involved in an e-government project. Together with the design of the $\mathrm{km}$ system, the project faced the issues of the organisational framework for maintaining the content and of community building among users.
\end{abstract}

\section{Problem Setting}

At the beginning of 2002 the Italian Government, through the Department of Innovation and Technology ${ }^{2}$, launched a call for proposals for e-government projects addressed to Regional andLocal Authorities. The call for proposal was aimed at funding projects based on Looperation among different levels of local Authorities. After the assignment of funds, Local Authorities are now in the position of carrying

1 The project has been carried out by a team lead by Giulio De Petra (Department of Technology and Innovation) and composed by Stefano Kluzer, Piero Luisi, Luca De Pietro (Formez) and Eugenio Nunziata, Roberta Morici, Gloria Sciarra (Butera e Partners).

2 The Department of Innovation and Technology- www.mininnovazione.it - provides support to the Ministry for Innovation and Technologies. The Ministry acts in the areas of technological innovation, the development of the information society and related innovations for government, citizens and businesses.

The original version of this chapter was revised: The copyright line was incorrect. This has been corrected. The Erratum to this chapter is available at DOI: 10.1007/978-3-540-44836-5_33

M.A. Wimmer (Ed.): KMGov 2003, LNAI 2645, pp. 304-309, 2003.

(C) Springer-Verlag Berlin Heidelberg 2003 
out the approved projects. For the purpose of providing them with appropriate support, specific organisational units have been introduced by the Department, called Regional Competence Centres (RCC). Their mission is to help Local Authorities in the implementation phase and to guarantee integration between different projects carried out in different areas of the Country. The RCC are mixed teams formed by both people from each regional area and people from the central government.

Although Local Authorities are autonomous in carrying out their projects, the Central government needs to maintain consistence among them without restricting their freedom. In this scenario the knowledge management system is created in order to support actors in keeping in contact, sharing resources, approaches, solutions and problems occurring in the implementation of e-government projects.

The benefit for Local Authorities is to have a chance to re-use experiences, to be guided in the implementation, to join a community of people involved in egovernment projects, to discuss and share problems and solutions. Specific goals of the KM system are:

- Create a network of all actors involved in e-government and information society projects, and support community building among them: Central and Local Governments, providers, professionals, researchers, etc;

- Provide a reserved workspace for RCC involved in supporting Local Authorities;

- Give visibility to resources on e-government and the information society in Italy in terms of documentation, events, discussions, hot issues, updates;

- Give visibility to the variety of projects and approaches on e-government implemented in different areas of the country.

\section{The Design Approach}

The design of the km system has followed an approach focused on two dimensions:

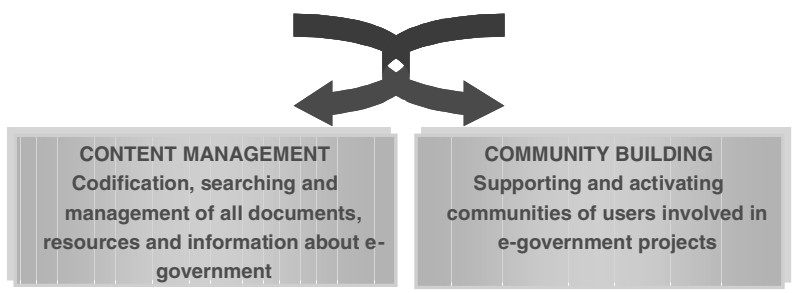

Fig. 1. The picture shows the concept of the KM system.

Content management issues have been addressed focusing on the creation of a knowledge map. The knowledge map represents a framework of keywords to classify, organise, access and retrieve all resources around the domain of e-government and the information society.

The map has been designed ad hoc for this system since no similar map was existing so far within the Department and the Ministry.

The map is a flexible tool, always evolving in order to follow the evolutions of the topic (e.g. introduction of new concepts or applications of e-government). It consists 
of four main domains which can be combined in order to classify each available resource in the system:

- "Type of Project" - the topics of e-government and information society projects

- "What to do" - Steps for the planning and implementing e-government and information society projects

- "How to do"- Tools, both technological and organisational, to carry out egovernment and information society projects

- "Where to do" - the level (Government vs. Local) where projects of e-government and information society can be carried out.

Each macro-area is articulated at a more detailed level, as the following picture shows.

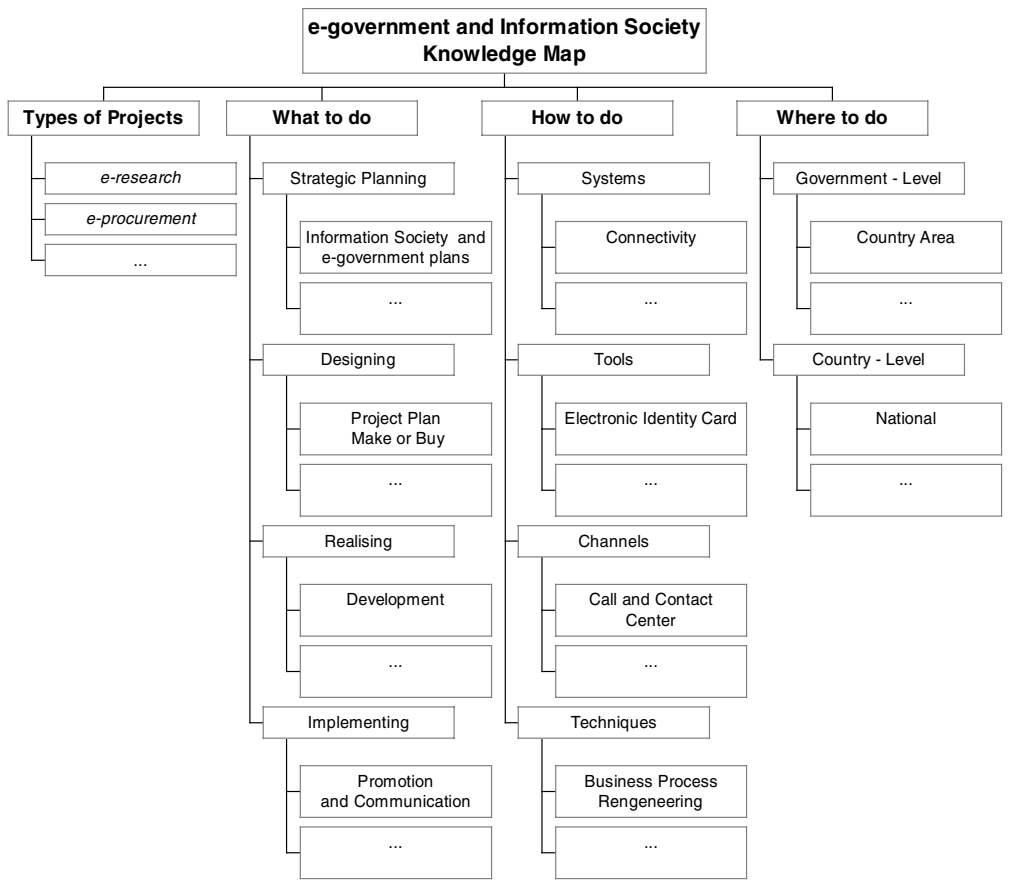

Fig. 2. The picture shows the main elements of the knowledge map.

Community building issues have been addressed focusing on the definition of actors and their roles in the KM system. The solution is designed for a network of actors operating both at local and at central level that need to cooperate and to share.

Different groups of users have been identified with different needs and roles; for each group some "user scenarios" have been designed in order to identify different types of resources and different functionalities.

In order to promote and encourage community development, the system is oriented to problem solving starting from specific knowledge needed in specific e-government projects and during specific project's phases.

The groups are:

- Regional Competence Centres and Central Staff: these are mainly representatives of the Innovation Department acting both at the local and the central level, whose 
role is to assist Local governments during the implementation phase. Their main activities are:

- Codification and Upload of documents

- Organise events

- Answer Local Governments and users requests

- Facilitate discussion spaces and animate the community

- Coordinate with the other Regional Competence Units

- System Management

- Local Authorities, made of representatives of Local Governments involved in the implementation of e-government projects. Their role is to carry out e-government projects. Their main activities are:

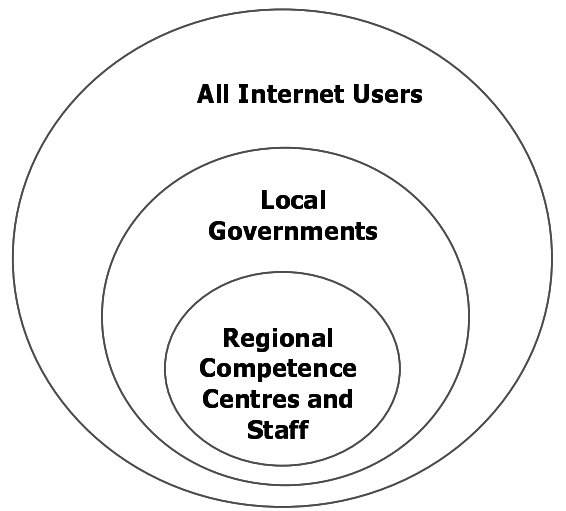

- Implement e-government projects

- Orientation and access to specific documentation

- Communicate and exchange opinions and resources with a community of other actors implementing e-government projects

- Contribute to the system (input of documents and resources)

- Participate to a regional workspace with dedicated resources

Fig. 3. The picture shows the main users of the system.

- All Internet users: these are all local and central Administration, external actors (Universities, providers, etc...) and people interested in the subject. Their need is to be informed about e-government and to carry out the following activities:

- Access and browse public content

- Input events and documents

- Contribute to the discussion within the community

- Request to join a workspace

- Be informed about new topics and about "what is going on" in egovernment.

\section{The km Solution}

The solution consists of three different environments, one for each group of users: the more a user is involved in e-government projects, the more resources are available. The three environments reflect different levels of access: a public level, a registered level, a private level (working space). A specific interface has been designed for each environment, even if consistency of design has been respected. 
The Regional Competence Centres and Central Staff have mainly access to the Back-office environment. The group has the widest access to the system resources, and can input and modify all the resources (the Regional Centres can only work on local level, the Central Unit can work on everything). The group works on content and site management and on community building.

The Local Authorities uses an online environment with local resources accessible with password; the environment presents both content and community functionalities. The Working Areas have the following functionalities: Be aware of who is online; Document management; Event notification; Shared agenda; Address book; Chat; Forum.

Internet users have access to the Internet site (with registration) where they can: Browse resources (according to knowledge map criteria); Search (mixing different knowledge map criteria); Personalise the navigation according to interests; Read the most voted; Send to a friend; Vote; Comment and discuss; Add documents (central staff filter).

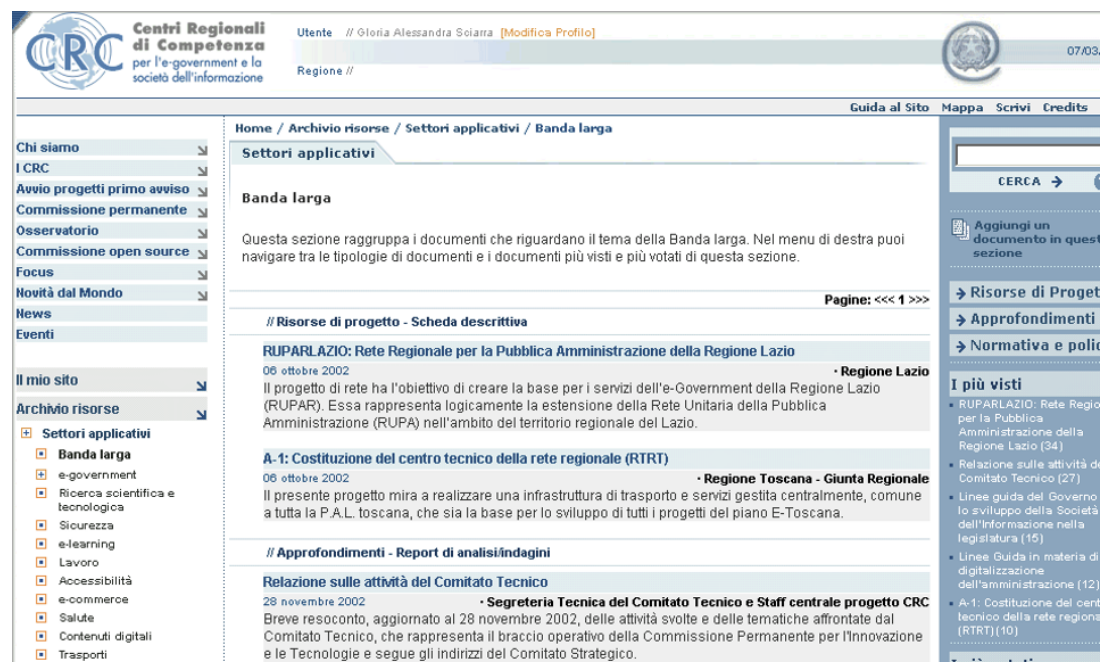

Fig. 4. The picture represents a screenshot of the KM system, accessible online at www.crcitalia.it

\section{The Design of Organisational Specs}

In order to guarantee maintenance of the system, an organisational framework has been designed. The central staff is responsible for feeding the system with contents, retrieving existing materials on e-government (laws, articles, papers, projects, etc) and to classify them according to all dimensions of the knowledge map. The central staff is in charge of quality control of documents submitted both from local staff and from other users of the system, and of the updating of knowledge map according to new topics emerging in the e-government domain of knowledge. 
The local staff - Regional Competence Centres - is responsible for feeding the system with contents coming from projects' implementation (plans, strategic documents, design of services, etc.) and for the updating the section regarding their activity within the territory they belong to.

The registered users to the website could submit documents (which are afterwards checked by central staff before the publishing).

The network and the community will be built with the support of training, experimentation and continuous involvement.

A program of training and involvement is being deployed especially with the Regional Competence Centres.

Various meetings have been carried out in order to explain all the system features and to observe the system in use; findings from these meetings will be used for further training sessions and for fine tuning the system.

Some communication actions will be carried out in order to give visibility of the system to the generic public.

Some further specific organisational actions will be adopted. Some of them are:

- Identifying specific roles of experts responsible for site sections to check contents;

- Monitoring knowledge map evolution;

- Supervising the homogeneous use of classifications;

- Identifying specific policy and actions to develop the "community" section, besides the "content" one;

- Spreading capabilities of activating and promoting community;

- Identifying moderation and coordination modalities within workspace.

\section{References}

1. Albolino S., Mesenzani M., Multimedia Interaction for Learning and Knowing: inspirational knowledge management to create value for individuals in organisations, TAKMA (2002).

2. Albolino S., Morici R., Schael T., Sciarra G., "A KM solution for the empowerment of Local Authorities", international Workshop "Knowledge Management in e-government KMGov2002" (2002).

3. Amy Jo Kim, Community Building on the Web: Secret Strategies for Successful Online Communities, by, Paperback, (2000).

4. Butera, F., L'organizzazione a rete attivata da cooperazione, conoscenza, comunicazione, comunità: la R\&S. Studi Organizzativi. 2(6):99-130 (1999).

5. De Michelis, G. Cooperation and Knowledge Creation, in Knowledge Emergence: Social, Technical and Evolutionary Dimensions of Knowledge Creation. In Nonaka I. and Nishiguchi T. (eds.): Cooperation and Knowledge Creation, Oxford University Press Inc (2001).

6. Kluzer S., Pizzicannella R., De Marco A., E-Government Project in Italy "A network of Regional Competence Centres (RCC) to support collaboration among Italian Public Administrations in the development of e-government" OECD Seminar 23-24 September (2002).

8. Wenger E., Communities of practice, learning meaning and identity, Cambridge University Press, New York, (1998). 